\title{
O ritmo frenético e instável do "eu": "ser" é um cálculo (in) provável
}

\author{
Tatiana Prevedello ${ }^{1}$
}

RESUMO: O foco deste artigo é a análise das figurações identitárias, regidas pelo signo do provisório e pela convicção da instabilidade, na poesia da artista e intelectual portuguesa Ana Hatherly. O objetivo é verificar como a variação, aliada ao diálogo que se estabelece entre identidade e subjetividade na escrita, configura as múltiplas formas de criação que entrelaçam, entre muitos outros recursos estéticos, a tradição e a modernidade no trabalho poético de Hatherly.

ABSTRACT: The focus this paper is to analyze of the identity figuration, governed by the sign of provisory and conviction of the instability in the poetry of the portuguese intellectual and artist Ana Hatherly. The aim is to see how the variation, together with the dialogue established between identity and subjectivity in writing, configure the multiple forms of creation that intertwine, among many other aesthetic resources, tradition and modernity in the poetic work of Hatherly.

PALAVAS-CHAVE: Identidade; Provisório; Ana Hatherly.

KEYWORDS: Identity; Provisory; Hatherly.

A Ambiguidade é a Arte do Suspenso. Tudo o que está suspenso suspende ou equilibra. Ou instabiliza. Mas tudo é instável ou está suspenso. Pelo menos ainda. Ainda é uma questão de tempo. Tudo depende da noção de tempo ou duração ou extensão. A aceleração do tempo pode traduzir-se pela imobilidade, pois que a imobilidade pode traduzir-se por um máximo de aceleração ou um mínimo de extensão: aceleração tão grande que já não se veja o movimento ou o espaço ou a duração. Tudo está sempre a destruir

1 Doutoranda em Literaturas Portuguesa e Luso-Africanas pela Universidade Federal do Rio Grande do Sul (UFRGS). Pesquisa: "Da expressão do tempo ao estilhaçar do eu: figurações da memória na escrita antuniana", sob a orientação da Prof. Maria da Glória Bordini. Contato: t_prevedello@hotmail.com 
tudo. Ou qualquer coisa. Ou alguém. Mas estamos sempre a destruir tudo ou qualquer coisa. Ou alguém.

Os construtores demolem. No lugar onde estava o sopro, pormos pedras ou palavras: sinónimo de construção. Ou destruição. Ou acção.

(Ana Hatherly, O Mestre)

\section{Algumas considerações para "calcular" a identidade na poesia de Ana Hatherly}

As questões que focalizam a problemática relacionada à identidade humana configuram-se como princípios articuladores de intensas reflexões em diferentes territórios do conhecimento, principalmente na atualidade, a qual se apresenta em meio a profundas transformações históricas e fenômenos sociais de grandes proporções. Aliase a essas perspectivas a sofisticação dos recursos tecnológicos, que se instaura como ponto intersectivo entre a celeridade que permeia o processo de evolução e a obsolência quase simultânea desses meios. Os contínuos e ininterruptos acontecimentos que envolvem o cenário contemporâneo têm posto em discussão as tradicionais formas de identidade, como a do sujeito cartesiano, concebido como "pensante e consciente, situado no centro do conhecimento" (HALL, 2002, p. 27). Esse motivo cria uma arena propícia para o surgimento não de uma identidade centrada, unificada e coerente, mas de identidades fragmentárias, instáveis e em permanente construção.

O olhar que, aqui, pretendemos direcionar à poesia de Ana Hatherly foi previamente filtrado por questões concernentes a relação entre identidade e subjetividade na escrita. Para pontuar essas indagações traçou-se uma delimitação exaustivamente explorada pelos estudos culturais e, ainda assim, questionável e imprecisa quanto a sua categorização: a escrita feminina. Não buscaremos, agora, mapear os desdobramentos, fendas e rasuras que se abrem quando um assunto tão controverso é colocado em cena; nem tampouco fazer imergir da poesia de Hatherly elementos que estejam a demarcar algum posicionamento estigmatizador, condicionado como escrita de mulher. Nem mesmo manifestamos o intuito de nos valermos de hipóteses que poderiam conduzir a uma resposta estável para a questão que, empregando um trocadilho que remete a obra da autora eleita para esse estudo, está suspenso no título: "ser" é um cálculo (in) provável? Já se professou que "discutir sobre a existência de uma escrita de mulher, ou mesmo escrever como mulher revelar-se-ia, assim, um ofício absolutamente inútil e, ao mesmo tempo, de extrema relevância." (AMARAL, 2003, p. 119). É alheio a nossa vontade atribuir possíveis cotações 
cambiais ou mensurar a carga valorativa contida nas expressões "absolutamente inútil" e de "extrema relevância" no universo da lírica feminina. O alvo para o qual miramos, cuja incerteza de poder atingi-lo encontra ressonância em nossos propósitos, atenta-se em procurar identificar na voz poética de Hatherly "diferentes combinações" que, num possível jogo de expressão identitária, corpo e gênero se entrelaçariam em versos da autora que se instauram como motivos organizadores para esta reflexão.

Os poemas concretistas de Hatherly, produzidos entre 1959 e 1989, foram incluídos na antologia Um calculador de improbabilidades (2001), que reúne textos poéticos caracterizados como experimentais. A definição de improbabilidade utilizada pela autora apresenta pontos de conectividade a de Abraham Moles, o qual na obra Teoria da informação e percepção estética explica que, para mensurar, de forma a priori a originalidade de algo, o único recurso que o raciocínio lógico disponibiliza é considerar a improbabilidade deste fato, pois "a certeza de ocorrência de uma mensagem ou de um acontecimento dado nada ensina ao receptor e não pode modificar o seu comportamento. [...] a informação ou a originalidade é função da improbabilidade da mensagem recebida" (MOLES, 1969, p. 41).

O trabalho poético de Hatherly ao subverter a sintaxe, a semântica e a grafia da linguagem, interpenetrando, de forma híbrida, o verbal e o não-verbal, apresenta novas formas de escrita e leitura que requerem, também, a compreensão de que se está, como a própria autora afirma, diante de um "jogo lúdico, racional e experimental, como todas as dimensões do signo, que envolve o visual, o som e o sentido" (HATHERLY, 2004, p. 74). A escrita "reinventada" de Hatherly compõe-se de múltiplos elementos que incluem releituras de textos clássicos e um permanente diálogo com a tradição literária, bem como a incorporação de recursos visuais e sonoros, colhidos na caligrafia, tipografia, música e pintura. Nesse panorama múltiplo, construído por uma artista versátil, o que se almeja é reconhecer na poesia desta autora marcas identitárias que, presumivelmente, não estariam filiadas a um gênero exclusivo, mas suscetíveis de serem contempladas sob o viés da variação e instabilidade impressas nos múltiplos motivos de uma poesia que sinaliza que "toda a criação é provisória” (HATHERLY, 2001, p. 132).

\section{2. "A sua forma é o momento": recombinação e instabilidade}

O fazer poético de Ana Hatherly resulta de uma atividade literária que envolve investigação da linguagem e da realidade existencial que permeia o universo da artista. Pode-se inferir que sua poesia é conduzida por pulsões de natureza erótica e pela vontade que se expressa em conceber o texto como uma máquina pensante. Em Um calculador de improbabilidades os poemas evidenciam interferências que Hatherly opera em seus versos, os quais são elaborados de forma orientada e passam por 
processos de supressão de palavras, superposições visuais e sintáticas, além de técnicas de permutas, variações e outras maneiras de apresentação da ordem sintática, sonora, semântica e visual do poema.

O vínculo nítido com o classicismo português, expresso na escolha de modelos consagrados pela lírica trovadoresca, permite depreender que a atividade poética de Hatherly não sugere um rompimento com o passado, o que poderia ser coerente com a sua atitude vanguardista, mas revela um trabalho de permanente releitura deste passado, objetivando conservar ativa a força motriz de sua poesia inventiva. E, conforme, as palavras da autora: "inovar é sempre relativo e tanto se pode inovar com o novo como inovar com o antigo, porque a invenção é uma forma de reinvenção, toda a leitura é uma forma de releitura e toda releitura transforma" (HATHERLY, 1995, p. 14). A respeito do mecanismo de criação poética, Hatherly tece considerações sobre as regras que envolvem os cálculos que esta opera:

A consciência dos mecanismos de criação e da comunicação poética, que se procura atingir através do ato poético, está submetida às regras que o poeta a si próprio impõe e que são as normas do jogo que ela executa e persegue com ideias, palavras e atos. Nesse contexto, o criador surge como um investigador de forma e de sentidos, que são as improbabilidades que ele calcula. O poema, como objeto-ato, é o resultado de um conjunto de regras aplicadas a uma situação específica (HATHERLY, 1995, p. 8).

Os textos poéticos que integram Tema e variações mostram que a relação dialógica com a música ocorre não apenas no âmbito da exploração fonética da língua ou da tessitura sonora dos poemas. Realiza-se uma organização estrutural, cujos procedimentos podem ser sintetizados na recombinação de um mote, o que resulta em uma série prismática de permutações. A variação representa uma modalidade musical cuja melodia é repetida no decorrer da composição, com alterações nos elementos que a constituem, permanecendo a possibilidade do ouvinte identificar o tema original. A variação literária ou poética é normalmente utilizada como uma técnica de desenvolvimento mais ou menos livre, que se apoia no seu assunto ou tema através de um elo essencialmente semântico. Este tipo de relação entre o tema e a sua variação é muito mais complexo na literatura do que na música. Ainda assim, a variação enquanto técnica de escrita apresenta princípios e procedimentos de construção similares nas duas artes. O texto poético que passa pela variação relaciona-se com sua fonte original através de processos de sinonímia, metonímia, paráfrase ou ainda outros, desencadeia relações semanticamente analógicas com o seu tema e o retoma sem recorrer exatamente aos mesmos signos. 
A elaboração formal do poema apresenta um sentido estrutural e os indícios que orientam o percurso para a sua leitura e interpretação, pois como Hatherly considera, "um dos princípios basilares de todo o Experimentalismo é o da concepção e aplicação de um programa, que valida e fundamenta todo o processo criativo, desde a concepção à execução" (HATHERLY, 1995, p. 14). Tema e variações é apresentado por Hatherly, a partir de um programa que informa ao leitor a organização estrutural e as intenções subjacentes aos versos, o qual está descrito dessa forma:

\section{Programa:}

Nestes poemas a experimentação consiste em partir de um mote, geralmente oferecido no título ou no início do poema, cuja glosa ou variação vai realizar-se na ordenação das palavras-chave ou do poema em diferentes combinações, de modo a criar um clima de inebriante incerteza, um estado de perturbação próprio de uma emoção intensa (HATHERLY, 1995, p. 122).

O repertório de recursos estilísticos do qual a voz poética se vale em seu trabalho possibilita olharmos a composição artística sob múltiplos ângulos, tal como é sugerido no próprio programa de apresentação. E, aqui, interpõe-se o desafio de conciliar a liberdade de leitura, o sentido geral do texto e as figurações identitárias que buscamos delinear na poesia de Hatherly. Tema e variações, após a apresentação do programa, estrutura-se em cinco partes não intituladas, mas ordenadas em blocos poéticos bem delimitados e designados pelos algarismos romanos I, II, II, IV e V. Os versos do mote inicial, contidos na primeira parte do poema, são recombinados e graficamente redimensionados nos blocos poéticos subsequentes:

O pio de uma escondida ave me anuncia na paisagem a vibração do ar.

Logo me cresce essa presença da espessura etérea da distância logo se move e se ondula e o canto das ramagens flutua em círculos que se alargam e se anulam É uma estranha água em que mergulho que como a água/ a outra que sustento se afunda me cobre e me envolve em penumbra de som que luz é ela e movimento mas forma a sua forma é o momento (HATHERLY, 1995, p. 122). 
As imagens que o poema nos apresenta sugerem movimento e evocam um eu lírico performático, mutável e instável, suscetível a se mesclar com os elementos advindos das "pulsações" efêmeras apresentadas na paisagem. Conforme postula Auerbach, as ações do instante cênico, evocadas pelos versos do poema, podem transmitir "uma energia das mais marcantes e plásticas", pois "é esta energia dos gestos e das atitudes que é mirada, evidentemente, pela representação, ao subdividir os acontecimentos em muitas parcelas plásticas" (AUERBACH, 1971, p. 99). As marcas identitárias subjacentes aos versos expressam um "eu" que, aparentemente, se harmoniza com a paisagem natural e, tal como está, deixa-se absorver e abstrair-se pelos elementos da natureza. Há de se convir, contudo, que estamos diante de um "eu" cuja identidade muda de papéis e não se fixa sobre um ponto estável, uma vez que "sua forma é o momento".

Um possível jogo de máscaras poderia ser depreendido dos versos "a outra que sustenta e afunda/ me cobre e me envolve em penumbra", revelando as figurações de um "eu" que, de forma simultânea, articula os papéis suspensos em suas múltiplas faces: àquela que, por um instante se mostra e se sustenta; a outra (ou todas as outras), que estão submersas ou envoltas em sombras durante uma fração temporal igualmente célere e suscetível a mobilidade.

Considerando que o poema oferece subsídios para entendermos que existe um "eu" mutável, cuja identidade não está cristalizada e, tal como a paisagem recebe influência da intensidade do ar, das vibrações sonoras, dos jogos de luzes que alteram continuamente o elemento sensorial que privilegiam, a tentativa de identificar a voz ou as marcas de uma identidade feminina mostram-se, senão falhas, pelo menos questionáveis. Bauman, ao analisar as concepções pós-modernas de indivíduos, constrói a metáfora da liquidez, caracterizada pela precariedade, incerteza e rapidez de movimento: "os líquidos, diferentemente dos sólidos, não mantêm sua forma com facilidade [...], os fluídos não se atêm muito a qualquer forma e estão constantemente prontos (e propensos) a mudá-la" (BAUMAN, 2005, p. 8). A metáfora da liquidez proposta por Bauman, utilizada para compreender as cambiáveis e relativas posições do sujeito pós-moderno, encontra um reflexo nas discussões concernentes ao gênero de Butler que, ao compreender as atuações do gênero como um ideal regulatório admite:

são as instabilidades, as possibilidades de rematerialização, abertas por esse processo, que marcam o domínio no qual a força da lei regulatória pode se voltar contra ela mesma para gerar rearticulações que colocam em questão a força hegemônica daquela mesma lei regulatória (BUTLER, 1999, p. 154). 
O que identificamos, portanto, em Tema e variações, são as atuações de um "eu” que não privilegia ou especifica qualquer marca de gênero. E, diante de um "eu" fluido, descentrado, o qual se distende, contrai-se ou se anula movido pelas impulsões instantâneas da paisagem que o envolve, a discussão sobre qualquer conotação sexual atribuída ao sujeito lírico se inviabiliza, uma vez que este se encontra simbioticamente envolvido em um texto regido pelo propósito da instabilidade. Em versos que são combinados e recombinados, organizando intercâmbios semânticos, a intenção estrategicamente calculada que é expressa no programa se realizada. A utilização de uma técnica clássica de composição poética, que oferece um mote "cuja glosa ou variações vai realizar-se na ordenação das palavras-chave", ao ser redimensiona por Hatherly inclui também as glosas do eu poético nas quais as flutuações dos papéis e posicionamentos identitários pairam sempre sob uma atmosfera de "inebriante incerteza".

\section{Ser e estar por enquanto: "toda a criação é provisória"}

As diversas possibilidades de construção de sentido na poesia de Ana Hatherly oferecem, entre o risco e o cálculo intencionalmente projetados pela autora, a rejeição de certezas definitivas, pois seu espaço é o da instabilidade criadora. Essa desordem fecunda rompe com "ordem tradicional, que o homem ocidental acreditava imutável e identificava com a estrutura objetiva do mundo" (ECO, 1976, p. 23), e a incerteza se transforma no principal critério para o entendimento da realidade.

Os versos de Eros frenético que recortamos para ilustrar, neste espaço, as nossas reflexões sobre o corpo como metáfora do provisório e instável nas representações identitárias mostram que a mediação do mundo pela arte sustenta uma visão crítica das conveniências e dos sentidos cristalizados das palavras. O Experimentalismo, ao rejeitar qualquer convenção, revela um posicionamento estético ideológico de liberdade sobre tudo o que possa modelar a poesia e prendê-la em fórmulas estáticas. Qualquer sentido sedimentado, aceito e representado pelo status quo, passa a ser concebido como uma interferência no processo de percepção do universo.

O poema Eros Frenético, ao compor um quadro que metaforiza a união sexual, nos mostra relações análogas entre o corpo e a máquina, as quais se interpenetram e se confundem em um movimento progressivo e sistemático que sugere, simultaneamente, automatismo técnico e biológico; a consciência dos limites que ambos - corpo e máquina - estão condicionados ao destino que os leva, inexoravelmente, à desintegração e a obsolência; e à libertação que a morte oferece, uma vez que tudo é provisório. À tessitura poética são entrelaçados termos advindos das mais diversas 
ciências, como a astronomia, física, química, biologia, engenharia mecânica. Essas implicações estéticas rompem com a ideia da simples repetição mimética do real visível. Aqui não há mais espaço para a figuração de uma identidade discursiva e determinista em relação ao mundo, passível de ser apresentada como uma metáfora que sugira o conhecimento de alguma verdade sólida. A sofisticação dos instrumentos e elementos científicos capazes de neutralizar os fundamentos basilares de qualquer verdade se desloca, no poema, em contínuas inversões e sobreposições entre homem e máquina.

O primeiro enquadramento que desejamos observar em Eros frenético refere-se à constituição instrumental do corpo sob o progresso da sociedade industrial, o que permite relacionar pulsões biológicas vitais e, sobretudo, eróticas, ao automatismo dos indivíduos. São, aqui, evocadas figuras de seres humanos que, na relação erótica, se assemelham a máquinas, reproduzem algumas de suas funções e forjam um mundo artificial de automação:

Na noite absolutamente não se via nada na terra e no céu nem um só satélite.

As máquinas dormiam.

Suas bocas caladas exalavam o cheiro acre do combustível muito quieto aguardando as próximas violentas combustões.

As máquinas repousavam as suas válvulas escuras e os lubrificantes cumpriam seu trabalho lento de estarem ali nos interstícios da matéria sinóvia escorregadia macia e totalmente aderente.

Eles estavam sentados em cadeiras e apoiavam seus braços sobre o tampo da mesa placa de madeira que assentava na extrema fragilidade das suas quatro patas provisórias.

\section{$[\ldots]$}

Eles estavam ali sentados em frente um do outro e no silêncio dos xilemas do tampo da mesa alimentavam a provisória vida dos seus corpos aparentes cuja particularidade trágica consiste em não lhes ser possível ocupar simultaneamente o mesmo espaço. Seus corpos mecanicamente equivaliam os satélites que certamente percorriam o espaço.

Seus motores internos tinham ali sido colocados com o fim específico de darem notícia do que encontrassem em sua trajectória no tempo espacial nunca esquecendo que interesse significa distância. O seu interesse era avaliar a distância que separa todos os corpos e toda as coisas umas das outras de modo que o espaço deixando de ser o incomensurável pudesse tornar-se mensuravelmente fasto para as interessadas trocas gasosas digo frenéticas etimologicamente espirituais ou etéreas. Eles estavam ali sentados em frente um do outro e 
suas trocas gasosas se cumpriam regularmente.

Digo freneticamente

(HATHERLY, 2001, p. 130-131).

O plano visual apresentado em Eros frenético desdobra-se em sucessivas e ininterruptas metamorfoses que fazem do provisório a sua própria categoria de criação. Isso anula a ideia de algo finalizado e instaura o transitório no local onde, em conformidade com uma perspectiva clássica, estaria sob vigência do eterno e imutável. $\mathrm{O}$ fragmento aqui transcrito nos mostra que a voz poética se vale de uma referência explícita à visão aberta pelo racionalismo cartesiano, que consolidou a relação constituída pela díade corpo-máquina e ocasionou uma nova imagem biomecânica do corpo humano. Segundo Descartes, tudo poderia ser explicado ao convocar-se o mecanismo dos membros, vísceras e músculos do corpo (DESCARTES, 1990). O princípio cartesiano configura um exemplo paradigmático de significativas consequências para a ulterior situação do corpo na cultura ocidental, pois a máquina humana de Descartes buscou o despojamento de todo mistério. Assim, se anteriormente o corpo constituía algo quase desconhecido, a partir do Iluminismo a explicação científica o reduz ao funcionamento de uma máquina. No emblemático signo da provisoriedade, que inúmeras vezes é evocado por Hatherly - "patas provisórias", "assentando em igualmente provisórias patas", "mutação provisória”, "a provisória vida dos corpos aparentes"; "emaranhadas nas patas provisórias" -, há o ceticismo que reconhece que o destino da condição humana não cabe mais nas representações cartesianas, pois aqui homem e máquina, embora se entrelacem em aparentes relações simbióticas, ocupam o reino da obsolência, instabilidade e incerteza.

Os sujeitos poéticos, de caráter provisório e indefinido, se manifestam no âmbito do poema por meio de ações que, como eclipses, sobrepõem e encobrem movimentos, de modo que uma descrição pode opor-se a outra, não se pautando em nivelamentos maniqueístas. Há pluralidade e equivalência nas descrições que emergem do mundo do poema. Esse modelo subjetivo reflete uma noção de visualidade fundamentada na materialidade do próprio corpo sempre instável e fugidia.

Podemos observar que o "eu" coerente, equilibrado e consciente, ou o sujeito cartesiano, cede lugar para que venha à tona dessas águas um sujeito problemático e contraditório, incapaz de fixar uma "ancoragem estável no mundo social” (HALL, 2002, p. 1). No espaço do poema corpos, textos e gestos são recombinados, de modo que Hatherly reconstrói um universo simbólico e relacional em torno do amor e da sexualidade humana. Em conformidade com a tradição filosófica ocidental, Eros é compreendido como uma divindade de ligação. O relacionamento entre erotismo e poesia mostra que o primeiro representa uma poética corporal e a segunda uma erótica verbal. O erotismo, para Octavio Paz, é sexualidade transfigurada em metáfora, pois "a 
imaginação é o agente que move o ato erótico e o poético. [...] A imagem poética é o abraço de realidades opostas [...] a poesia erotiza a linguagem e o mundo porque ela própria, em seu modo de operação, já é erotismo" (PAZ, 1995, p. 41).

Nos versos de Eros frenético contemplamos um artefato artístico desafiador que, ao valer-se da similitude contida na díade corpo-máquina, articula o princípio da razão predominante, invoca a sensualidade e a liberdade criadora em oposição à repressão. Conforme as palavras da autora proferidas em uma entrevista:

O poema que dá o título ao livro «Eros frenético» teve um impacte negativo tremendo. As pessoas estavam habituadas a falar do amor num enquadramento romântico, do século XIX. Esse texto é erótico, mas a imagística é a da máquina. Isso ofendeu muita gente, como se o corpo não fosse uma máquina, uma máquina sofredora (HATHERLY, 2003, p. 1).

É preciso destacar que a qualidade transgressora do discurso erótico que elabora a sexualidade mostra um saber cuja natureza é dual, pois se refere à individualidade e à configuração da diferença que apenas se concretiza no contato com o outro. O corpo próprio e o alheio revelam-se também por meio de uma percepção multi sensorial dos elementos que os envolvem, pois podemos ver a expressão de uma sensualidade voraz e vertiginosa e, ao mesmo tempo, disseminada e refratária. Isso possibilita que a temporalidade e as delimitações espaciais integrem muitos tempos e espaços em um único instante, orientando-se pelas ondulações rítmicas de "nunca haver limite para a voracidade de dois/ corpos quererem ocupar o mesmo espaço dentro/ da máquina do corpo do outro onde tudo é noite" (HATHERLY, 2001, p. 132).

A indeterminação entre as fronteiras que constituem o plano da máquina e do homem sob uma intensa perspectiva erótica talvez consista na simulação da voz que tece o texto poético ao manipular, de modo rigoroso, as unidades significativas contidas nas relações simbióticas de Eros frenético. Não é possível detectar indícios que queiram fornecer visões totalizantes, pois as identidades sexuais, embora pulsantes, não são claramente definidas. E, sob a regência da provisoriedade, seus papéis ou funções também não são definitivos ou imutavelmente distribuídos. O movimento frenético, ardente e sensual envolve, então, os corpos-máquinas no ápice do gozo erótico: "freneticamente esquecidos da entropia que se prepara/ para abrir a boca e dar uma gargalhada enorme/ quando os corpos se encontram julgando perder a propriedade mágica da coesão da matéria na vertigem" (HATHERLY, 2001, p. 132).

Uma mudança de paradigma dessa natureza reformula também a concepção do sujeito poético e configura novos sentidos à linguagem verbal e visual na poesia tecnológica experimental contemporânea. A libertação da ordem estética, instaurada 
pelo rompimento da linearidade, inovações na representação da imagem, exploração lúdica da linguagem, entre outras, expressa uma manifestação transgressora diante da realidade. Não se torna difícil, por conseguinte, identificar, na lírica hatherliana, uma ligação entre o novo código estético e uma atitude ideológica de subversão dos valores vigentes, inclusive no que se refere às representações do corpo e a indeterminação de gênero na composição da identidade do sujeito poético.

\section{Ininterruptas e cambiantes operações de um cálculo não concluído}

A poesia de Ana Hatherly sugere liberdade de pensar o mundo, a escrita e o indivíduo como seres mutáveis, híbridos, contraditórios, que não estão fixos ou imobilizados em nenhuma hierarquia ou sistema atemporal de valores. Essa mobilidade é, talvez, o ponto essencial para a compreensão de seu projeto artístico, entendido como work in progress que recusa a vocação para o permanente e incorpora a instabilidade e a mutação como eixos de construção formal e de leitura, numa metáfora oblíqua de nosso próprio estar no mundo: um conjunto de culturas desunificadas, contingente, instável, indeterminado, e que, por essa razão, suspeita de noções clássicas de verdade, razão, identidade e objetividade, da ideia de progresso ou emancipação universais, das estruturas únicas ou bases definidas de explicação.

Os exercícios artísticos, orientados por esse mesmo postulado, põem em movimento formas discursivas indeterminadas, provisórias, abertas e irônicas, além de outros procedimentos que se relacionam ou se confundem como a ambiguidade, a destotalização, a descontinuidade, a disjunção, entre outros. Esses procedimentos estratégicos têm tonificado um número impar de produtos culturais na atualidade. A arte contemporânea apresenta a tendência de aceitar e procurar atribuir formas à provocação do acaso, do ambíguo, do (in) provável.

Esses aspectos são revelados pelo desenvolvimento de hipóteses teóricas que se sustentam na indeterminação, na probabilidade estatística, nos modelos explicativos provisórios e variáveis. Artistas como Hatherly têm procurado mapear com seus artefatos estéticos essa desordem. Todavia, como Eco (1976, p. 23) destaca, esses aspectos não remetem a "derrota de toda possibilidade ordenadora", mas fazem emergir uma desordem fecunda, que objetiva romper com a ordem tradicional, unívoca e fechada, e estimular a fruição da obra de arte que se faz, simultaneamente, inventiva e aberta.

A obra artística de Hatherly, portanto, é aberta a múltiplas interpretações. Amparada no aspecto plurissignificante da linguagem, questiona o seu estatuto exato ou seu potencial para compreender o mundo em sua complexidade. A transcendência buscada pelos poetas experimentais reveste-se, ainda, de um caráter contra ideológico 
em relação aos cânones e modelos impostos, revelando, por meio de uma subversão na escrita, uma recusa dos valores estabelecidos.

A poesia moderna é, por excelência, o espaço do desafio, instaura a ruptura das convenções da normalidade, desloca o conhecimento institucional para os sentidos e a subjetividade, desestabiliza qualquer forma de categorização. Hatherly é uma artista que transgride os limites impostos pela normatividade convencional, rompendo as formas tradicionais de articulação da voz poética e representações dos sujeitos no espaço do poema, que não se fixam em uma identidade estável e se abrem para diversas possibilidades interpretativas que, como defendemos, não estão presas em categorização estereotípicas de gênero. $\mathrm{Na}$ poesia de Hatherly os signos designam polissemias imprevisíveis, complexos sentidos que ultrapassam a fixidez linguística e são reapropriados por uma voz poética que não assume um discurso deliberadamente feminino.

O gesto artístico de Hatherly é híbrido e convoca a escrita, a pintura, a música e o pensamento sob o signo do indeterminado, capaz de dissolver qualquer delimitação entre essas expressões criativas. Seu movimento inovador constitui uma profunda renovação do universo constituído das artes e, inclusive, de acepções estigmatizantes que poderiam ser regidas como escrita feminina. A expressão que marca o "idioma" poético de Hatherly localiza os limites tênues que, da poesia ao desenho, questiona a fronteira das artes, dos gêneros artísticos e, provavelmente, do próprio gênero, reinventado na tessitura das "diferentes combinações". Neste complexo exercício de cálculo sobre a instabilidade do "eu" e do fazer-ser artístico as possíveis fórmulas para orientar uma resolução estável e concluída não poderiam, de outra forma, mostrarem-se senão falhas. Seguir o fio tênue de uma autora que escreve um desenho, traça um poema ou, na sua sutileza inventiva, registra o movimento de corpos-máquinas frenéticos e igualmente delimitados e provisórios, atingimos uma artista plural que nos mostra como "estamos forçosamente incompletos, desunidos e seremos obscuros uns para os outros e para nós próprios" (HATHERLY, 1995, p. 53).

\section{REFERÊNCIAS BIBLIOGRÁFICAS:}

AMARAL, Ana Luísa. "Do centro e da margem: escrita do corpo em escrita de mulheres". In: AMARAL, Ana Luísa; VILLAS-BOAS, Gonçalo; FREITAS, Marinella et al. Cadernos de Literatura Comparada 8/9: literatura e identidades. Porto: Instituto de Literatura Comparada Margarida Losa, 2003, p. 105-120.

AUERBACH, Erich. Mimesis: a representação da realidade na literatura ocidental. São Paulo: Perspectiva, 1971.

BAUMAN, Zygmunt. Modernidade líquida. Rio de Janeiro: Jorge Zahar, 2005. 
BUTLER, Judith. Gender trouble: feminism and the subversion of identity. New York and London: Routledge, 1990.

BUTLER, Judith. "Corpos que pesam: sobre os limites discursivos do sexo". In: LOURO, Guacira Lopes (Org.). O corpo educado: pedagogias da sexualidade. Belo Horizonte: Autêntica, 1999. p. 151-172.

DESCARTES, R. El tratado del hombre. Madrid: Alianza Editorial, 1990.

ECO, Umberto. Obra aberta. São Paulo: Perspectiva, 1976.

GASTÃO, Ana Marques. "Ana Hatherly: meditações sobre escrita e ato criador". Revista de Cultura Agulha. n. 35, ago. 2003. São Paulo. Disponível em: <http://www.revista.agulha.nom.br/ag35hatherly.htm>. Acesso em: 30 jul. 2010.

HALL, Stuart. A identidade cultural na pós-modernidade. $7^{\mathrm{a}}$. ed. Rio de Janeiro: DP\&A, 2002.

HATHERLY, Ana. O espaço crítico: do simbolismo à vanguarda. Lisboa: Caminho, 1979.

HATHERLY, Ana. A casa das musas. Lisboa: Editorial Estampa, 1995.

HATHERLY, Ana. O mestre. Lisboa: Quimera, $3^{a}$. ed., 1995.

HATHERLY, Ana. "Eros frenético". In: _. Um calculador de improbabilidades. Coimbra: Quimera, 2001.

HATHERLY, Ana. Interfaces do olhar. Lisboa: Roma Editora, 2004.

HATHERLY, Ana. "A experiência do prodígio: exemplos de textos visuais portugueses”. In: MAGALHÃES, Isabel Allegro de (Org.). História e antologia da literatura portuguesa: século XVII. Lisboa: Edição da Fundação Calouste Gulbenkian, n. 29, out. 2004, p. 17-21.

MOLES, Abraham. Teoria da informação e percepção estética. Rio de Janeiro: Tempo Brasileiro, 1969.

PAZ, Octavio. A dupla chama: amor e erotismo. 2a . ed. São Paulo: Siciliano, 1995. 